\title{
Construction of a Maxillary Prosthesis with a Hollow Obturator by the Balloon Technique and a Case Report
}

\author{
Junko HAYASHI ${ }^{1}$, Minoru NISHIYAMA ${ }^{2}$, Masahiko MIYAKE ${ }^{3}$, \\ Itsuro $\mathrm{KUDO}^{3}$ and Kiyoshi NAKAZAWA ${ }^{4}$
}

(Received 8 September and accepted 13 September 1989)

Key words: maxillary prosthesis, hollow obturator, balloon technique, ethylene vinyl acetate copolymer

\begin{abstract}
The authors devised a new method for making a maxillary prosthesis with a hollow obturator, which was named the Balloon Technique.

This new technique has a number of advantages over the conventional method in that it not only facilitates the molding of a soft plastic hollow obturator in a single process, but also simplifies the trial fitting of the completed obturator. Furthermore, it makes possible firm adhesion of the hollow obturator and the denture base by the hot-melt method while the denture base resin is cured. Finally, the completed maxillary prosthesis is extremely light.
\end{abstract}

\section{Introduction}

The viability of patients with malignant tumor has been improving recently because of progress in anesthesia and surgical techniques. Among efforts to help these patients return to normal social life, the importance of using maxillofacial prosthetics has been publicized, and the number of opportunities for their use is increasing.

The use of a prosthesis to fill a maxillary defect is usually aimed at restoring normal function. Its shape is therefore more complex than that of an ordinary denture, and its weight tends to be greater. When such a prosthesis has been inserted into the mouth, in many cases it lacks full retention and stability. Efforts are therefore being made to use polymer materials of low specific gravity, to apply more thought to the shape of the prosthesis, and to find easier ways of making and adjusting it $^{[1-8]}$.

The authors have devised a method of simplifying the process of making a prosthesis and of decreasing its weight. Using what we call the Balloon Technique for making a prosthesis with a hollow, a balloon-shaped object is first produced

\footnotetext{
林純子，西山實，三宅正彦，工藤逸郎， 中澤清：Dental Technician Training School ${ }^{1}$, Departments of Dental Materials ${ }^{2}$ and Oral Surgery ${ }^{3}$, Nihon University School of Dentistry, and Tokyo Metropolitan Center for Oral Health Dentistry Handicapped Patients ${ }^{4}$, Tokyo, Japan.

Correspondence to: Junko HAYASHI, Dental Technician Training School, Nihon University School of Dentistry, 1-8-13 Kanda-Surugadai, Chiyoda-ku, Tokyo 101, JAPAN
} 
from a thermoplastic ethylene vinyl acetate copolymer (EVA: ERKOFLEX), using a heat-press apparatus, and then the balloon is made to adhere to the denture base using a hot-melt process, while the methacrylate denture base resin is cured by microwave curing. This report describes this method of making a maxillary prosthesis with a hollow obturator by the Balloon Technique, and discusses one clinical case in which this prosthesis was used.

\section{Balloon Technique and Clinical Case}

1. Materials and Apparatus

Table 1 shows the materials and apparatus used in the Balloon Technique. The physical properties of ERKOFLEX are shown in Table $2^{[9]}$. As shown, no deterioration of the mechanical properties of ERKOFLEX was observed even after it was immersed in water at $37^{\circ} \mathrm{C}$ for 210 days. The amount of water absorption, moreover, was small. This suggests that this material would be very stable for use in the mouth for extended periods of time.

Figure 1 shows the strength of adhesion of ERKOFLEX to methacrylate resin ${ }^{[9]}$. As can be seen, this material, immersed in water at $37^{\circ} \mathrm{C}$ for 210 days, displayed a stable adhesive strength value of about $40 \mathrm{kgf} / \mathrm{cm}^{2}$. Judging from this, even in the environment of the mouth, this material is thought to maintain strong stable adhesion to methacrylate resin for a long period.

2. Preparation Method

1) Preparation of a Working Model (Step 1)

Following the usual procedures, the first step is to make a study model and an individual tray. Then next step is to make a working model by pouring dental stone in a slurry state into an impression produced through functional impressiontaking, using the individual tray. In this connection, the undercut area of the model used for retention of the maxillary prosthesis must be modified so that the sharp sections of the area are gently rounded (Fig. 2).

2) Formation of the Hollow Obturator and Baseplate (Step 2)

The first step is to fix the working model in the center of the ERKOPRESS flask. This is followed by molding of an obturator and a baseplate through a process of heating and pressurization after placing the ERKOFLEX plate above the model (Fig. 3). On this occasion, the state of the molding must be confirmed by removing the molded obturator from the model (Fig. 4). Also needed is a selection of plates in advance with thicknesses of $1.5,2.0,3.0$ and $4.0 \mathrm{~mm}$ so that the thickness of the molded obturator is not less than about $0.8 \mathrm{~mm}$.

The next step is to soften a separately prepared ERKOFLEX plate by heating its perimeter with a laboratory torch. This plate is to constitute the roof section of the hollow obturator. The diameter of the roof must be made some 2-3 mm larger than that of the concavity reproduced in the model. The softened ERKOFLEX plate is then joined to the already molded obturator, and the joined part is welded under pressure with a heated wax spatula. The welded part must be made smooth by a finishing process (Fig. 5).

3) Formation of the Occlusion Rim (Step 3)

The first step here is to set the molded hollow obturator and baseplate on the 
working model, and then to cover the entire palate and the alveolar ridge of the healthy side with sheet wax (GC, \#20), applied with uniform pressure. This process is necessary to facilitate easier removal of the wax when the stone mold is made in a later process (step 5).

The next step is to make the occlusion rim with paraffin wax following the usual procedures.

4) Preparation and Trial Fitting of the Wax Denture (Step 4)

A model made through bite-taking following the usual procedures is mounted on an articulator, after which artificial teeth and wax gum festooning are arranged to complete a wax denture (Fig. 6).

In conducting a trial fitting of the wax denture, in addition to normal inspection procedures, the state of fitting of the hollow into the concavity and the degree of retention and stability at the alveolar ridge on the healthy side must be confirmed.

5) Preparation of Stone Mold and Curing of the Denture Base Resin (Step 5)

The first process involved is to invest a wax denture with gypsum in an FRP flask (Fig. 7) by the usual procedures.

Following hardening of the gypsum, the next step is to divide the flask and to remove the wax with the fingers along the boundary between the ERKOFLEX plate and the sheet wax (prepared in step 3). The remaining wax must be washed away by pouring boiling water over it. At the time of wax removal, care should be taken to avoid pouring boiling water directly over the hollow obturator. The reason for this precaution is that the shape of the hollow risks change due to a sudden rise of temperature, since the material is thermoplastic.

Next, preparations must be made to make a denture base of the healthy side using methacrylate resin. This involves cutting off with a design knife (or a pair of scissors) the ERKOFLEX plate that covered the healthy side, and then applying a resin separation agent to the exposed surface of the stone mold (Figs. 8, 9). The next step following the preparation of the stone mold is to fill it with dough resin (ACRON MC: L/P 0.43) and to apply pressure to the filled resin. After pressurization, the flask is fixed by the bolts and nuts attached to it.

The flask is then placed in a microwave oven for curing of the resin for the denture base by 3 min of microwave irradiation.

6) Removal and Polishing of the Maxillary Prosthesis (Step 6)

Removal of the maxillary prosthesis following curing is done in the conventional manner. Polishing of the hollow part is not necessarily required (Fig. 10), but when the need for adjustment arises, polishing with a sandpaper cone is permissible (Fig. 11), as in the case of a denture base resin. The other parts are polished as for an ordinary denture to complete the maxillary prosthesis (Fig. 12).

3. Clinical Case

A maxillary prosthesis with a hollow obturator made by the Balloon Technique was applied in the following case.

Patient: Female, 70 years of age.

First examination: December 12, 1986.

Chief complaint: Leak of saliva from the cheek due to inadequate fitting of a 
maxillary prosthesis.

History of the present illness: She was diagnosed in 1982 as suffering from right maxillary sarcoma and underwent a hemimaxillectomy of the right maxilla, and ophthalmectomy of the right eyeball as well as tracheotomy, performed at a hospital otorhinolaryngology department, and received treatment with carcinostatic drugs and irradiation. Later, she received prosthodontic treatment for the defective part at a dental clinic.

Physiognomy: She was ranked $\mathrm{F}_{1234} \mathrm{C}_{34}$ under the $\mathrm{FC}$ classification ${ }^{[10]}$ (Fig. 13).

Oral findings: She was ranked $\mathrm{H}_{4} \mathrm{~S}_{0} \mathrm{D}_{2} \mathrm{~T}_{2}$ under the HS classification ${ }^{[11]}$. The patient's nasal cavity and sinus paranasales were found to be touching each other due to the defective half of the right maxilla (Fig. 14).

Treatment and progress: A maxillary prosthesis with a hollow obturator made by the Balloon Technique was inserted into the mouth (Figs. 15, 16, 17). This maxillary prosthesis has two major characteristics. One is the use of a soft, elastic balloon as an obturator, making it extremely light, $18.5 \mathrm{~g}$. The other is the prevention of saliva from leaking from the cheek, by setting in succession an escape route alongside the cervix on the buccal side of the denture base $\mathrm{e}^{[12]}$.

Through these measures, it became easy for the patient to insert or remove the maxillary prosthesis, as well as to wash it by herself. As the degree of adhesion at the defective palate was increased, ingestion of food became easier. In particular, it became easier for the patient to swallow pieces of soft, sticky bread and to masticate fibrous foods such as pickled vegetables.

Furthermore, the patient's pronunciation became clearer. No particular abnormality is observed now, one year after insertion of the maxillary prosthesis, which has enabled the patient to have a normal social life.

\section{Discussion}

It is very difficult to obtain good retention and stabilization of a maxillary prosthesis that is inserted into a maxilla bearing a major defect. It is usually natural to use teeth and the alveolar ridge of the remaining maxilla as objects for retention of this type of maxillary prosthesis. On the defective side, however, it becomes necessary to make active use of undercuts of the concavity ${ }^{[13]}$.

In choosing such a retention area in a concavity, it must be confirmed that the material and design of the maxillary prosthesis obturator produce no harmful effects or mechanical irritation in the oral system. Therefore, soft and elastic materials available for use in all types of undercuts are required in order to meet the demands for better retention ${ }^{[14]}$. Many kinds of polymer material such as silicone rubber, polyurethane rubber and fluoro-polymer are now being utilized. However, the process of making a prosthesis for a maxillary defect using these materials involves many difficulties. This has led to continued calls for simplification of the process of dental fabrication.

The authors therefore planned to simplify the method of making a maxillary prosthesis bearing a hollow, and devised the present Balloon Technique using a thermoplastic EVA. 


\section{Hollow Obturator}

The conventional processes for making a hollow obturator include: 1) A method of completing a hollow by first removing stuffing from an obturator made of methacrylate resin, and then covering up the outlet from which the stuffing was removed with self-curing resin ${ }^{[1-4,6-8]}, 2$ ) a method of completing a hollow by first creating a slightly smaller hollow by pasting together bowl-shaped objects made of methacrylate resin, and then wrapping it with denture base resin at the time of making the denture base ${ }^{[8]}$, or 3 ) a method of creating a hollow by attaching a bulb system used for tires to a latex rubber balloon ${ }^{[15]}$.

However, these methods involve several difficulties. For instance, method 1) requires the work of removing the stuffing during the fabrication process, as well as a complicated adhesion process. Method 2) requires repeating of the same formation process, since this involves production in advance of a hollow slightly smaller obturator. This method also makes it difficult to obtain a lighter prosthesis because of the duplex structure involved. Method 3) requires an adhesion process and a formation process involving attachment, in addition to the fact that the hollow cannot be reproduced as an object with a shape.

Compared to these methods, the Balloon Technique devised by the authors has the following advantages: 1) an obturator conforming to the shape of a defective part can be made in only one process of heat molding of EVA, 2) adhesion of a lid to create a hollow is very simple and adhesion is very strong, 3) the hollow is very light and 4) the hollow and the denture base can be attached firmly to each other through a hot-melt adhesion process at the time of heat-curing of the denture base resin. Judging from these merits, the authors are convinced that this method has removed many of the difficulties from the production process.

2. Post-Operation Progress

Usui et al. ${ }^{[16]}$ have pointed out that the function of a maxillary prosthesis is greatly influenced by such factors as good closure of the oral and nostril cavities, its weight, and ease of fabrication and adjustment. In the clinical case described in this report, closure was good, as required in a maxillary prosthesis, and the authors obtained satisfactory results with regard to lighter weight and easier fabrication and adjustment. Because of these merits, food ingestion became easier and saliva was completely prevented from leaking from the defective part of the cheek, while enabling the patient to have clear pronunciation, thus allowing her to return to normal social life.

In the present clinical case using the Balloon Technique, the patient is now showing satisfactory progress, one year after insertion of the maxillary prosthesis, with no apparent abnormality or harmful effects. It will be necessary to follow the patient's progress continuously. For the purpose of advising wider clinical application of this method, the authors are planning to study 1) the degree of undercut necessary for a hollow obturator of EVA, 2) the thickness desirable for it and 3) how to deal with the filling of a balloon with a gaseous body and its removal.

\section{Conclusion}

The authors have devised the Balloon Technique, a method of making a 
prosthesis with a hollow, which facilitates simpler dental laboratory work and better adhesion to the denture base resin.

Its major features are as follows:

1. A soft and elastic hollow obturator which can be molded in one step.

2. Trial fitting of the hollow obturator can be made after its completion.

3. The hollow obturator and the denture base resin are attached firmly to each other by a hot-melt method.

4. The maxillary prosthesis is lighter ( $18.5 \mathrm{~g}$ in the present clinical case).

In the meantime, in the clinical case we treated using this method, there has been an improvement in the patient's chief complaint, her mastication and pronunciation, thus enabling her to return to normal social life in a satisfactory condition.

\section{References}

[1] Ohyama, T., Gold, H. O. and Pruzansky, S.: Maxillary obturator with silicone-lined hollow extension, J. Prosthet. Dent., 34, 336-341, 1975

[2] Mizutani, Y., Ohnishi, M., Shimizu, M. and Shioda, S.: Newly devised immediate temporary obturator using transparent plastic plates, Maxillofacial Prosthetics, 2, 29-32, 1979 (in Japanese)

[3] Shimizu, M., TAniguchi, M. and TANaKa, Y.: A new type obturator by utilizing fluid resin, Maxillofacial Prosthetics, 3, 60-62, 1980 (in Japanese)

[4] Miyazaki, T., Ohnishi, M., Mizutani, Y., Komuro, C., Shioda, S. and W obturator plate for use in cases of hemimaxillar-hemifacial defects, Maxillofacial Prosthetics, 4, 158-162, 1981 (in Japanese)

[5] Sakamoto, Y., Mizutani, Y., Kimura, T., Shioiri, S., Shioda, S. and Ohnishi, M.: Functional restoration with bilateral obturating prosthesis for maxillary defects following a tumor operation, Maxillofacial Prosthetics, 7, 62-67, 1984 (in Japanese)

[6] Browning, J. D. and Kinderkneht, J.: Fabrication of a hollow obturator with fluid resin, $J$. Prosthet. Dent., 52, 891-895, 1984

[7] Kamoi, H., Kohama, G., Furuta, I. and Iwai, M.:Fabrication technique using oil clay of the maxillary prosthesis with light hollow obturator, Maxillofacial Prosthetics, 7, 34-40, 1984 (in Japanese)

[8] Imase, K., Onodera, S., Yoshikawa, K. and Hosoi, T.: Application of immediate maxillary prosthesis for hemimaxillectomy patients, Maxillofacial Prosthetics, 8 (2), 25-32, 1985 (in Japanese)

[9] Hayashi, J., Imai, N., Makita, K., Osakabe, J., NaKazawa, K., Mita, T. and Nishiyama, M.: Physical properties and adhesive strengh of ethylene vinyl acetate copolymer, J. Nihon. Univ. Dent. Tec., 7, 37-42, 1988 (in Japanese)

[10] Matsuura, M., Tanabe, T. and Seto, K.: A proposal for new classification (FC classification) of facial defects, Maxillofacial Prosthetics, 4, 17-22, 1981 (in Japanese)

[11] Matsuura, M., Nomura, T. and Seto, K.: Proposal for new classification (HS classification) of maxillary defects, Maxillofacial Prosthetics, 2, 15-21, 1979 (in Japanese)

[12] Hayashi, J., Makita, K., Osakabe, J., Y Ashiro, J. and Nishiyama, M.: A method for joining soft material with hard material on the maxillary prosthesis, Maxillofacial Prosthetics, 10, 6-11, 1987 (in Japanese)

[13] Nomura, T.: Clinical studies on prosthetic repair in cases of maxillary defect 1 . Investigations on causes of dissatisfied prostheses and their improvement, Japan, J. Oral. Surg., 25, 1355-1367, 1979 (in Japanese)

[14] Shirakawa, M., Kuroda, Y., Suda, I., Hasegawa, H., N Nakajima, S., Uzawa, S. and Tanabe, H.: Report on ten cases of prosthetic repair in maxillary defects, Maxillofacial Prosthetics, 5, 44-50, 1982 (in Japanese) 
[15] PAyne, A. G. L. and Welton, W. G.: An inflatable obturator for use following maxillectomy. J. Prosthet. Dent., 15, 759-763, 1965

[16] Usui, H., Shimozato, K., Sato, Y., Yoshikawa, Y. and Iida, S.: Report on five cases of maxillary prosthesis, Maxillofacial Prosthetics, 7, 123-129, 1984 (in Japanese) 
Table 1 Materials and apparatus used

\begin{tabular}{ll}
\hline \multicolumn{1}{c}{ Material and apparatus } & \multicolumn{1}{c}{ Brand } \\
\hline Balloon material & ERKOFLEX (ERKODENT) \\
Heat-press apparatus & ERKOPRESS (ERKODENT) \\
Heat-fusing apparatus & LABORATORY TORCH (GC) \\
Base plate material & BASE PLATE WAX (GC) \\
Denture base resin & ACRON MC (GC) \\
Dental flask & FRP FLASK (GC) \\
Curing apparatus & Microwave oven (SANYODEN- \\
& KI, EM-535T, 960W) \\
\hline
\end{tabular}

Table 2 Physical properties of ERKOFLEX

\begin{tabular}{lrc}
\hline \multicolumn{1}{c}{ Property } & \multicolumn{2}{c}{ Value } \\
\hline Hardness (Shore A) & 75.4 & $(1.9)$ \\
Tear strength $\left(\mathrm{kgf} / \mathrm{cm}^{2}\right)$ & 55.2 & $(1.3)$ \\
Tensile strength $\left(\mathrm{kgf} / \mathrm{cm}^{2}\right)$ & 133.7 & $(7.9)$ \\
Elongation (\%) & $990.0(47.9)$ \\
Young's modulus $\left(\mathrm{kgf} / \mathrm{cm}^{2}\right)$ & $75.7(10.4)$ \\
Water sorption $\left(\mathrm{mg} / \mathrm{cm}^{2}\right)$ & $0.18(0.02)$ \\
Coefficient of thermal & 168.8 \\
expansion (at $\left.40^{\circ} \mathrm{C}\right)\left(\times 10^{-6} /{ }^{\circ} \mathrm{C}\right)$ & \\
\multicolumn{2}{c}{ Storage in water at $37^{\circ} \mathrm{C}$ for 210 days ( ): S. D }
\end{tabular}

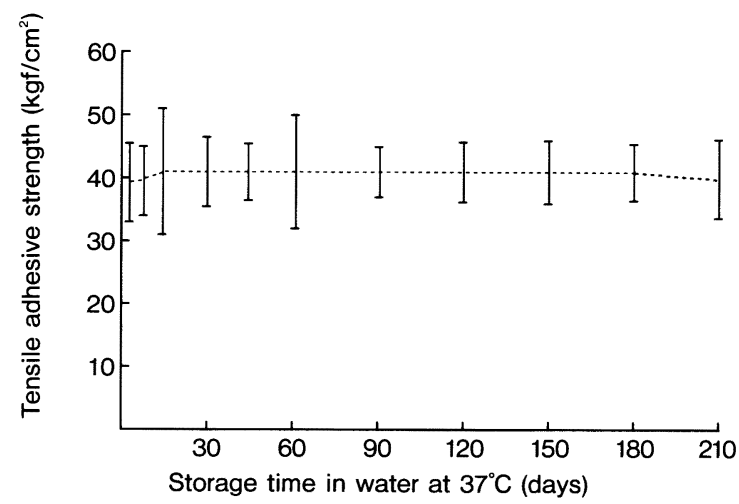

Fig. 1 Strength of adhesion of ERKOFLEX to methacrylate resin 


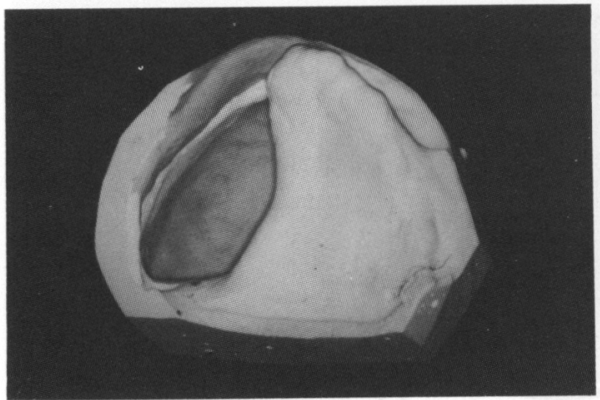

Fig. 2 Working model

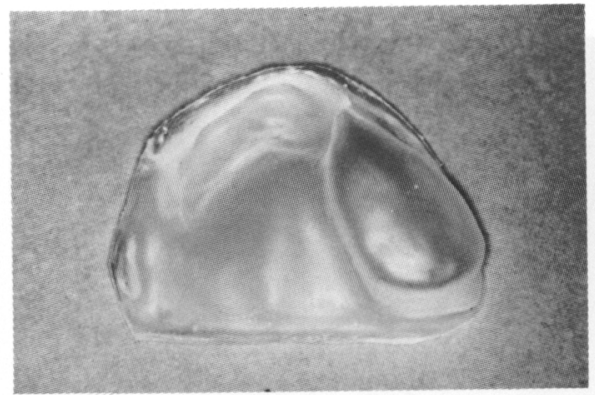

Fig. 4 Base immediately after pressing
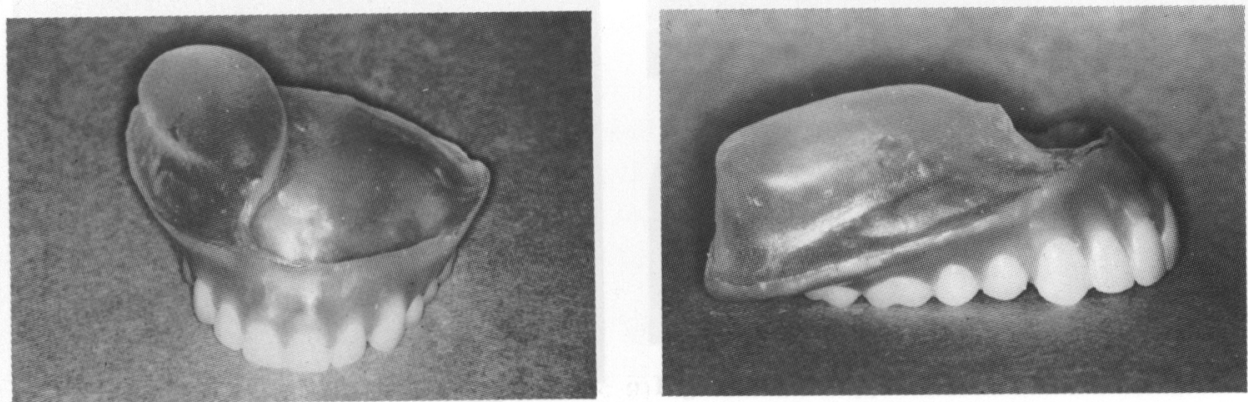

Fig. 6 Preparation of wax denture with hollow obturator

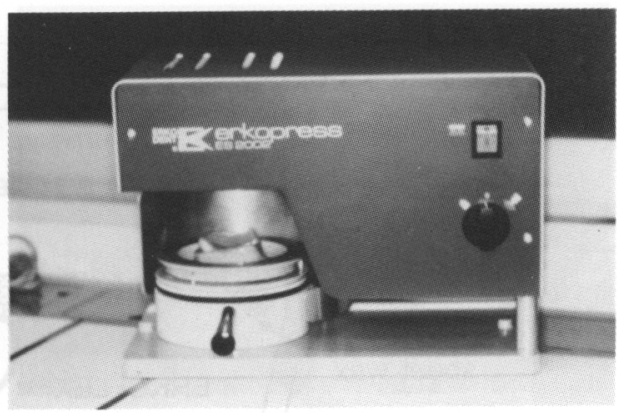

Fig. 3 Heat-press apparatus (ERKOPRESS)

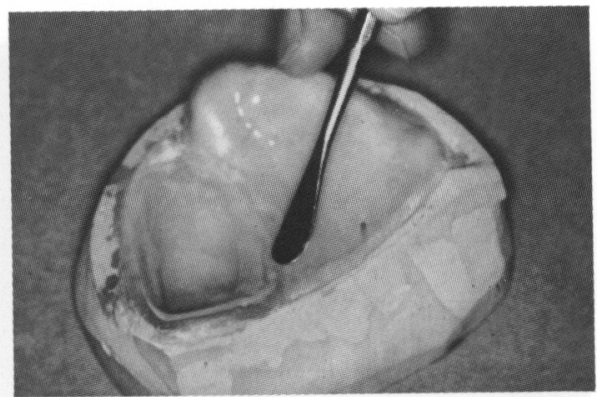

Fig. 5 Welding with heated spatula after softening of ERKOFLEX by laboratory torch 


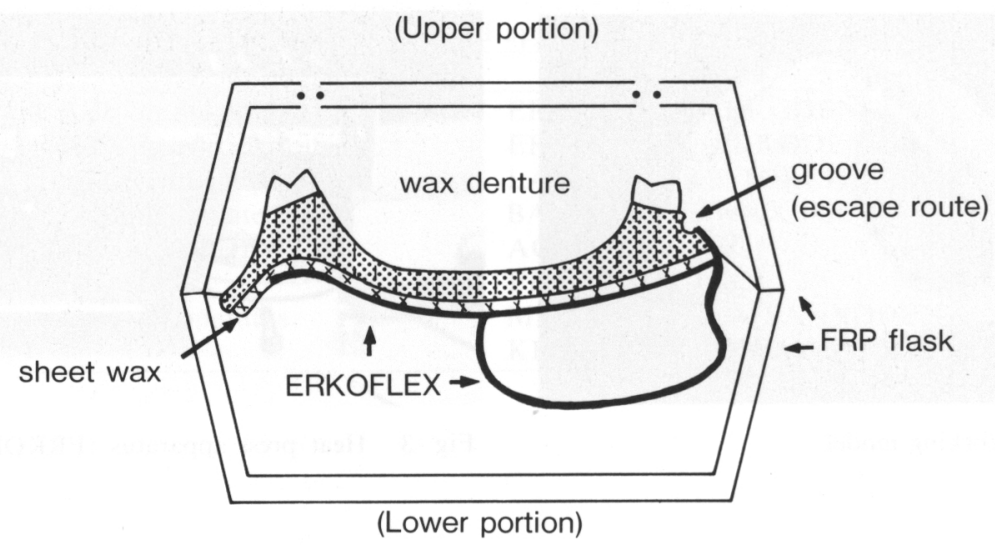

Fig. 7 Illustration of flasking

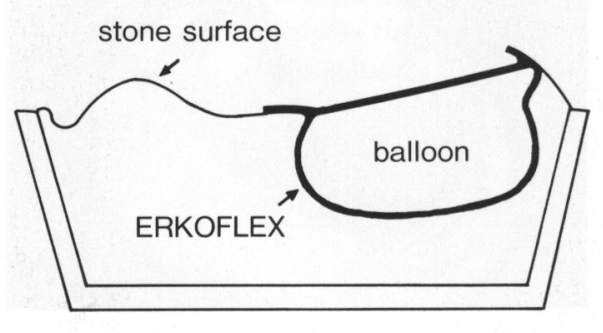

(Lower portion)

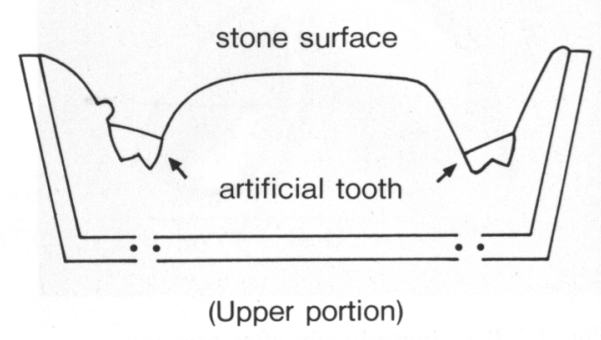

Fig. 8 Illustration of flasking after removal of wax
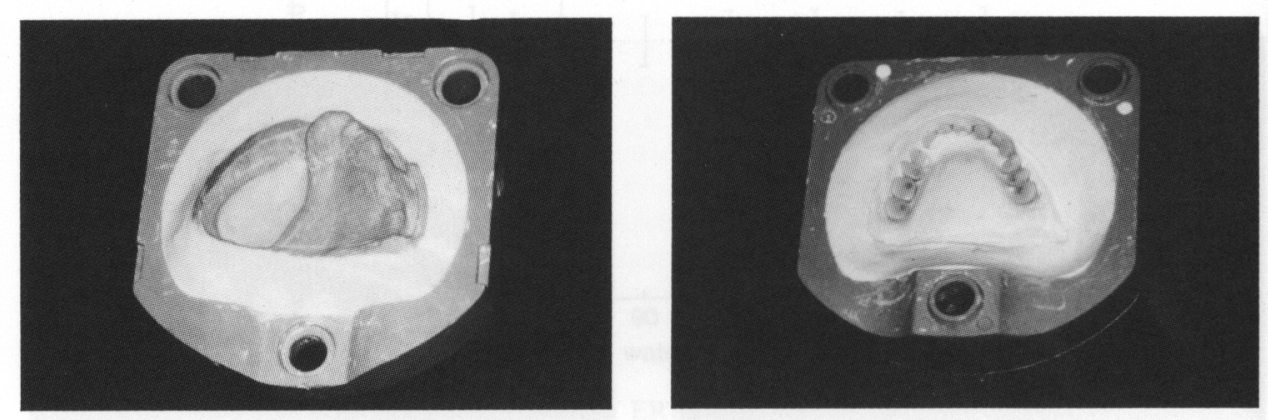

Fig. 9 Stone split mold (with hollow obturator removed) 


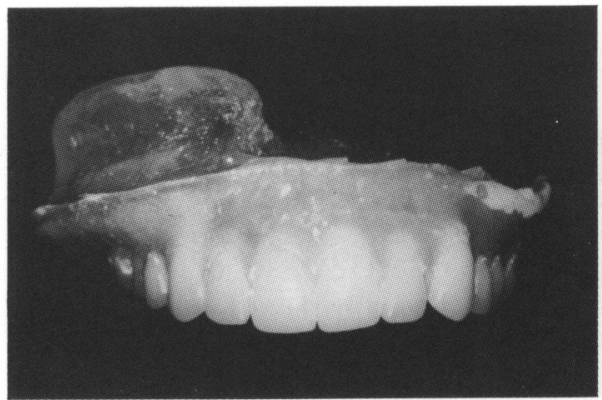

Fig. 10 Maxillary prosthesis immediately after removal from the mold
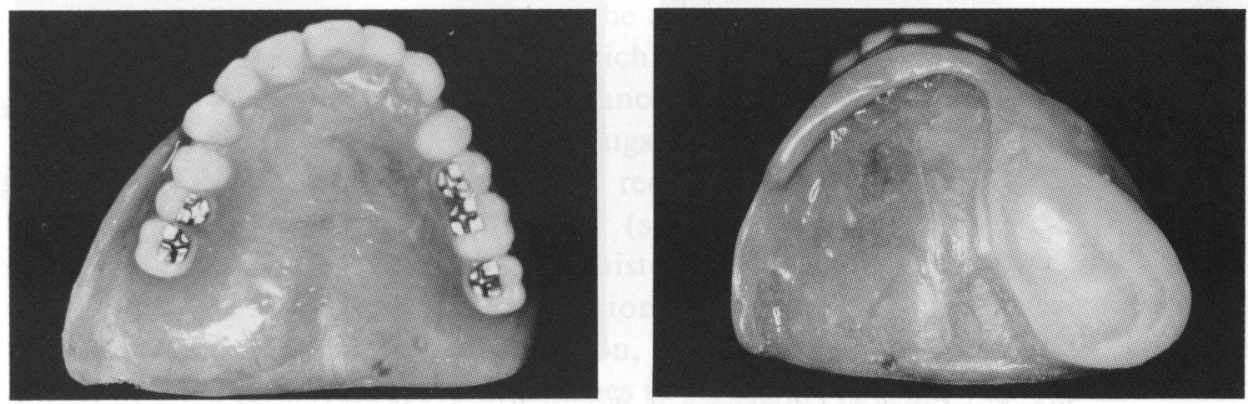

Fig. 12 Completed maxillary prosthesis (Left: occlusal surface, Right: saddle surface)
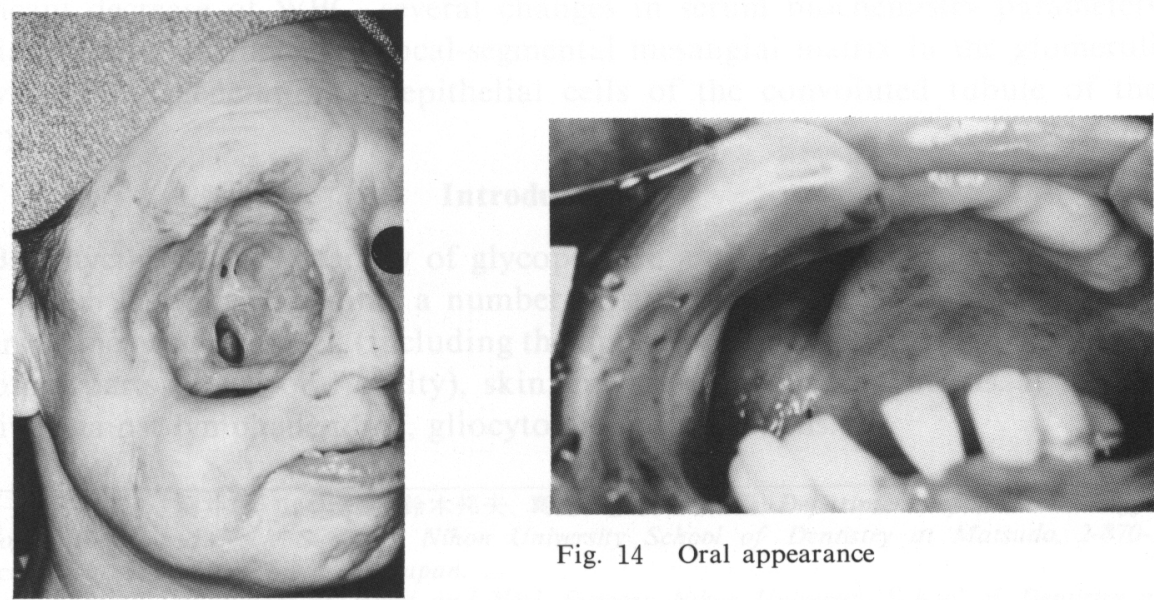

Fig. 14 Oral appearance

Fig. 13 Facial appearance 


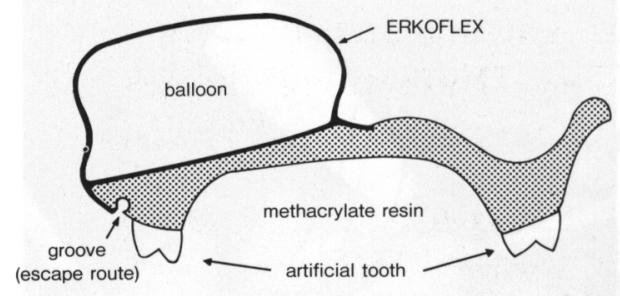

Fig. 15 Illustration of maxillary prosthesis with hollow obturator
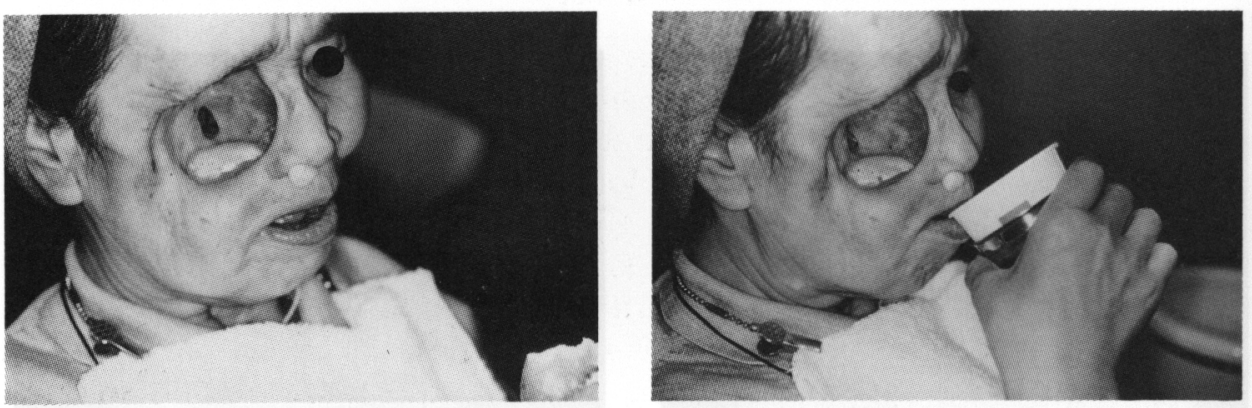

Fig. 17 Eating and drinking with the maxillary prosthesis in position 